\title{
PULMONARY METASTASES FROM CHONDROBLASTOMA OF THE TIBIA
}

\section{Report of a Case}

\author{
R. J. Riddell, ${ }^{*}$ C. J. Louis $\nmid$ and N. A. Bromberger, $\ddagger$ Melbourne, Australia \\ From the Austin Hospital, Heidelberg, Victoria, Australia
}

Benign chondroblastoma has been regarded as a subvariety of giant-cell tumour of bone and variously called cartilage-containing giant-cell tumour, calcifying giant-cell tumour, or epiphysial giant-cell tumour. Jaffe and Lichtenstein (1942) coined the name "benign chondroblastoma" and described eight cases. They stated that it was distinct from giant-cell tumour in that it occurred in the second decade, before the age of twenty, and had a distinctive cytological morphology and pattern. No malignant potentiality of these tumours had been observed by them.

A "benign chondroblastoma" of the upper tibial epiphysis, occurring in a patient at the Austin Hospital, was found to have metastasised to the lungs two years after a mid-thigh amputation of the leg. As this is a most unusual course in the natural history of such a tumour, the case is thought worthy of record.

\section{CASE REPORT}

A girl aged fourteen years first presented in 1968 with swelling, stiffness, pain and bouts of instability in the right knee. Although no definite abnormality was seen in radiographs of the knee, arthrotomy was performed six months later and the medial meniscus was excised.

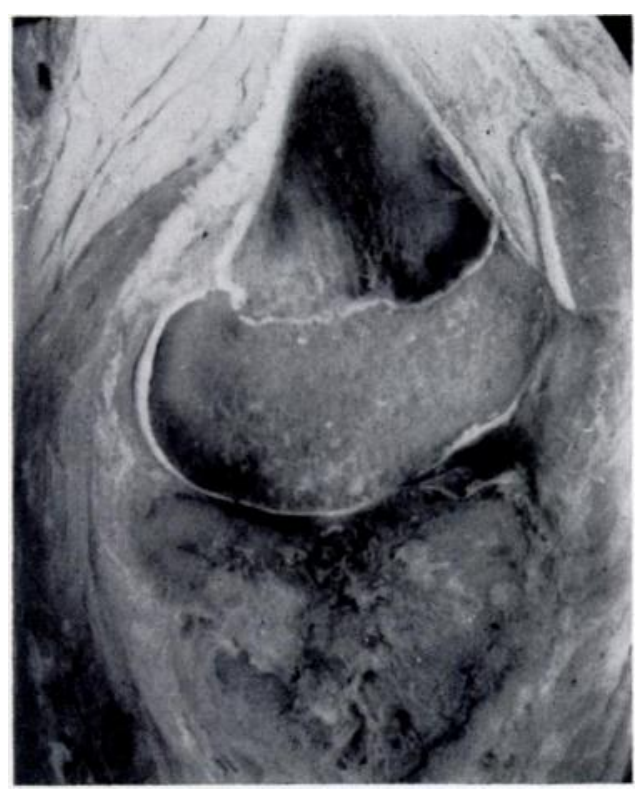

FiG. 1

The amputated specimen of the right leg sectioned in the mid-sagittal plane to show the neoplasm largely replacing the epiphysis of the tibia. Note the erosion of the articular cartilage.
No tissue was provided for histology on this occasion. The pain and stiffness failed to improve after operation.

Radiographs six months later showed an irregular area of sclerosis of the medial condyle of the tibia which extended posteriorly to involve the whole width of the tibia. There was a small area of calcification just above the articular surface of the tibia and an area of new bone formation behind the posterior shaft, superiorly. The tubercles were ill-defined. There was also a considerable amount of soft-tissue swelling on the medial side of the knee joint in relation to the upper tibia.

Open biopsy of the affected area of bone was done. Microscopic examination of the material removed showed a cellular tissue composed of small polygonal cells with clearly defined vesicular nuclei. Mitotic figures were sparse. Occasional multinucleated giant cells containing from five to ten nuclei, resembling those seen in giant-cell tumour of bone, were also present. Generally the tumour cells were closely packed together with little intercellular

\footnotetext{
* Director of Anatomical Pathology, Austin Hospital.

† Acting Professor of Pathology (Austin Hospital), University of Melbourne.

$\ddagger$ Honorary Orthopaedic Surgeon, Austin Hospital.
} 


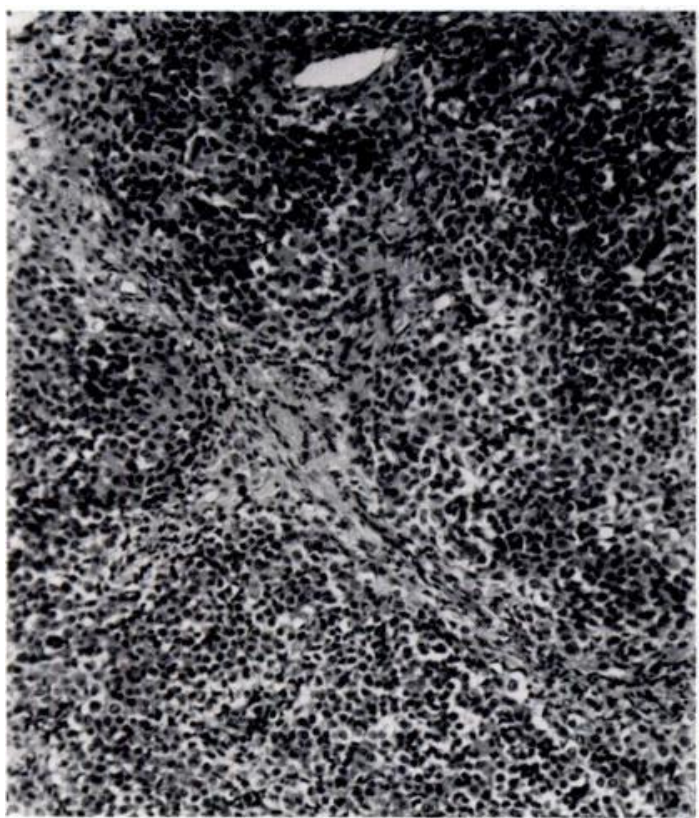

FIG. 2

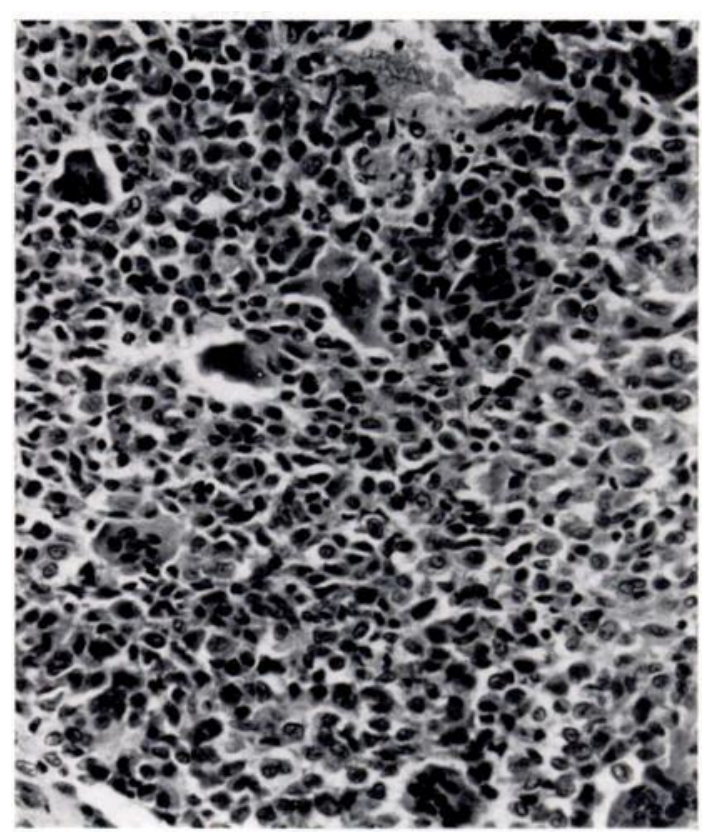

FIG. 3

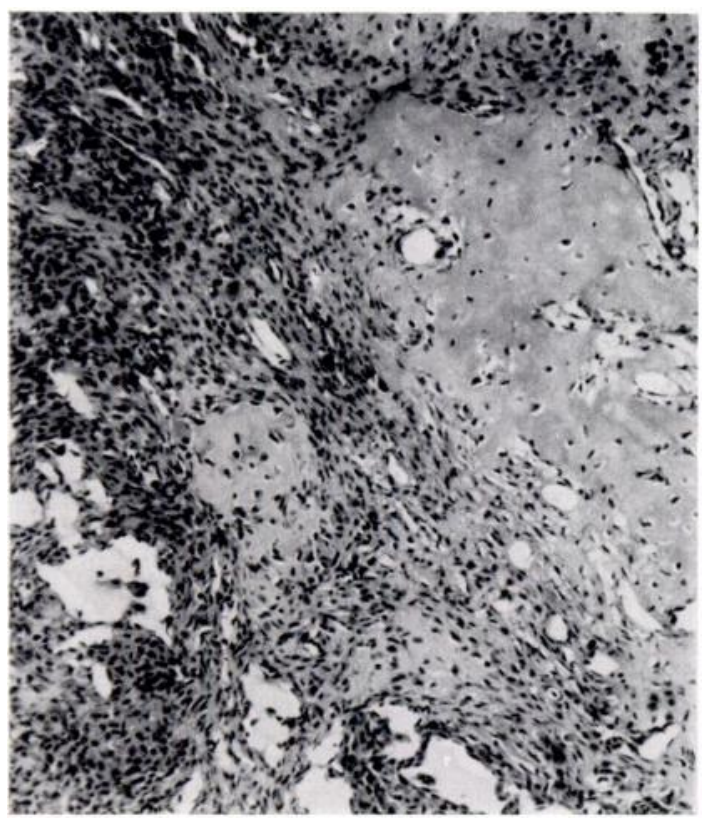

Fig. 4

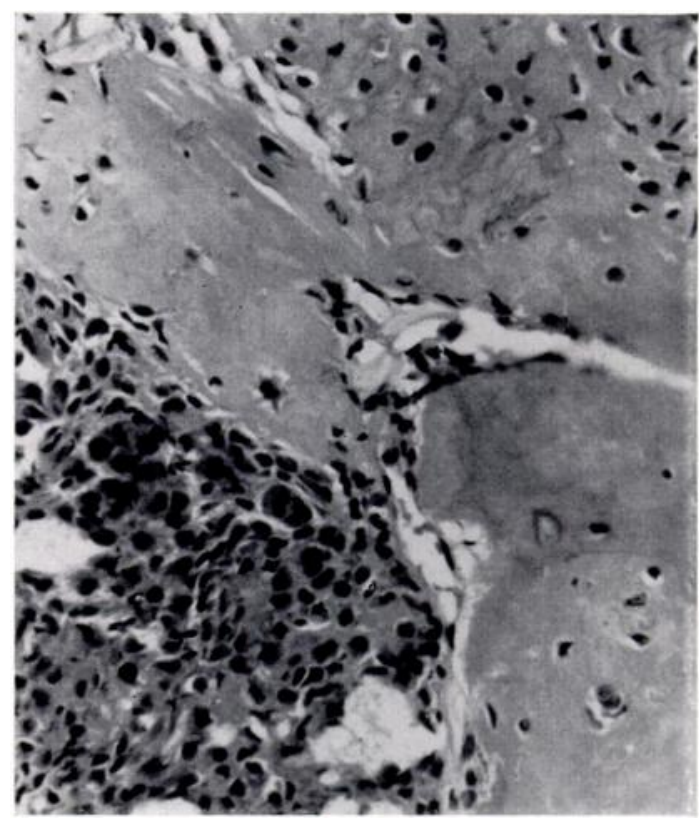

Fig. 5

Sections from the tumour shown in Figure 1. Figure 2-The structure was quite cellular with the tumour cells arranged in sheets and with homogeneous morphology. (Haematoxylin and eosin, $\times 100$.) Figure $3-$ To show the homogeneous cellular structure with many multinucleated giant cells. (Haematoxylin and eosin, $\therefore 400$.) Figure 4-Areas of cartilaginous-like stroma are seen. (Haematoxylin and ecsin, $\times 1 \mathrm{C0}$.) Figure 5Neoplastic cells in lacunae within the cartilage-like stroma can be seen, with faint pericellular calcification. (Haematoxylin and eosin, $\times 400$.) 


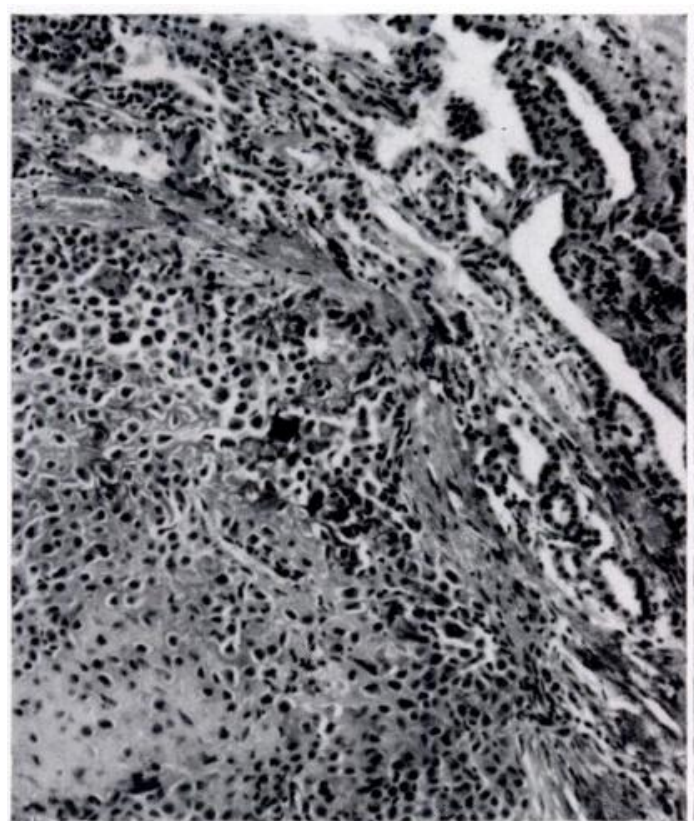

FIG. 6

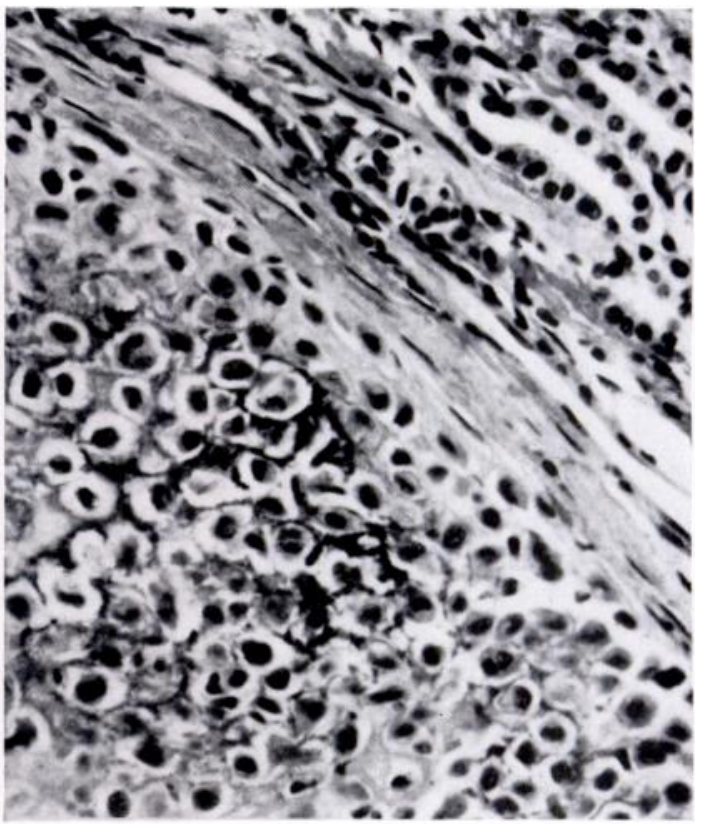

FIG. 7

The pulmonary metastasis. Figure 6-Shows the cellular structure similar to that of the primary bone tumour. Areas of cartilage-like stroma are seen. (Haematoxylin and eosin, $\times 100$.) Figure $7-$ To show the calcification around the neoplastic cells. (Haematoxylin and eosin, $\times 400$.)

stroma, but in some areas the stroma was more prominent and showed a cartilaginous appearance. The histological features were those of benign chondroblastoma.

Operation and progress - Two months later, in April 1969, conservative operation was decided upon. The tumour in the upper right tibia was curetted and a bone graft inserted across the cavity. The tissue removed showed histological features similar to those of the original biopsy. The knee remained stiff and painful and showed progressive limitation of flexion. Radiographs six months later showed that a shell of new bone had formed in relation to the medial tibial condyle and there was some bony destruction of the posterior aspect of the tibial plateau (Figs. 8 and 9). Soft-tissue swelling related to the medial condyle was consistent with callus formation but the appearance of the posterior part of the condyle now represented a possible malignant transformation. Femoral angiography showed the popliteal artery to be displaced somewhat laterally by a vascular mass in the upper end of the tibia (Fig. 10). The branches of the popliteal artery were stretched around the mass but the large surface veins contained very little contrast material. The leg was amputated through the mid-thigh on December 2, 1969.

Examination of the amputated limb showed a large neoplasm in the upper epiphysis of the tibia (Fig. 1). The tumour was approximately 5 centimetres in diameter, irregularly spherical in outline, consisting of homogeneous, encephaloid, light brown tissue. Anteriorly, the margin was not clearly defined, but inferiorly, the tumour had replaced the epiphysial cartilage and extended into the upper metaphysis. Posteriorly, the cortex was replaced by tumour tissue bulging into the soft tissues and showing a well-defined fibrous capsule. Above, the medial articular cartilage was also replaced by tumour tissue showing a smooth but rather lobular surface with irregular fibrous ankylosis extending through the joint. Microscopic examination of the tumour tissue showed a structure exactly similar to that of the original biopsy. The neoplasm was cellular and composed of small polygonal cells, closely packed together in sheets with clearly defined cell margins and little intercellular stroma. The nuclei varied slightly in size, but were vesicular and few mitotic figures were present. The stroma was sparse in many areas (Figs. 2 and 3 ) but in other areas it had a hyaline cartilaginous 


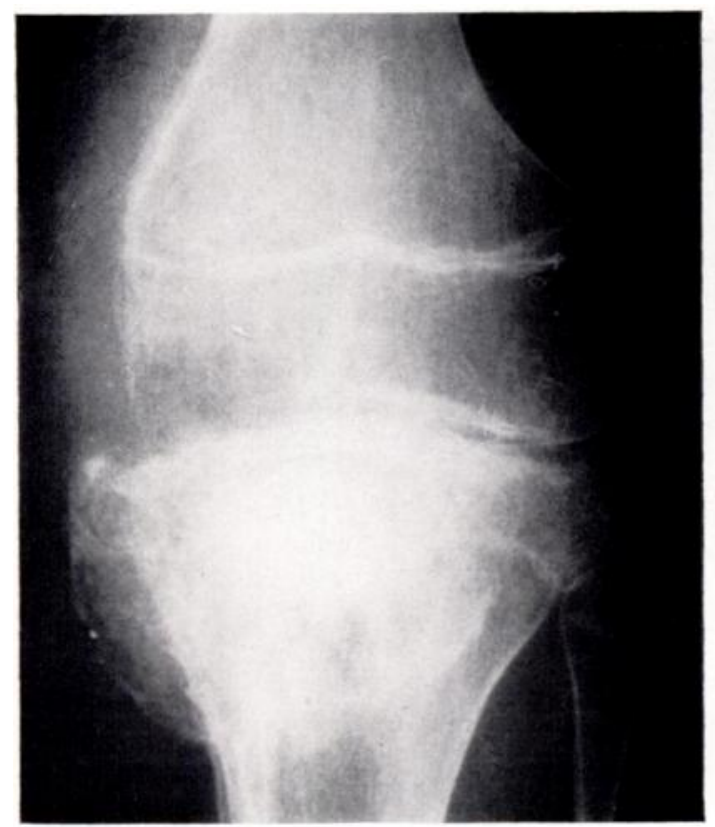

FIG. 8

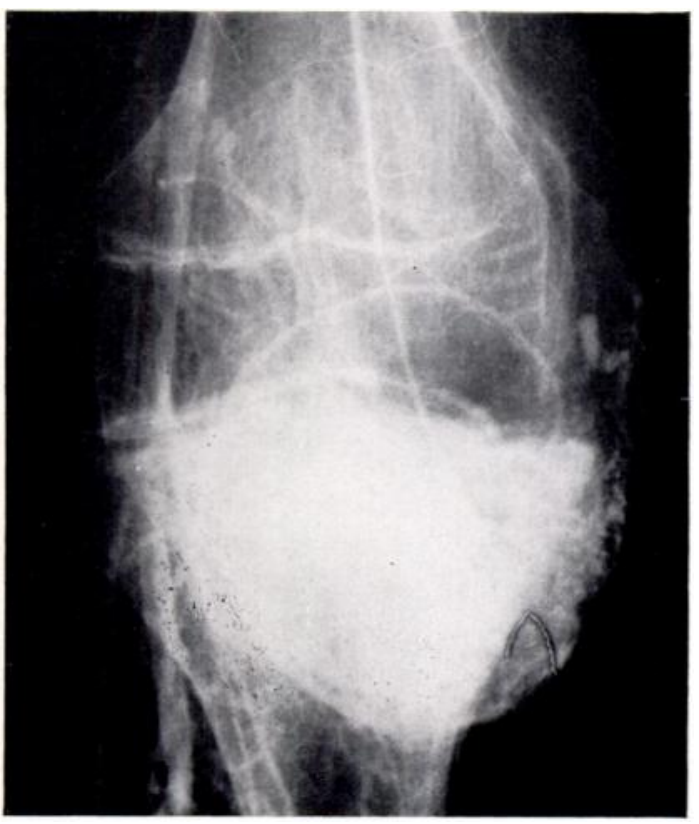

Fig. 10

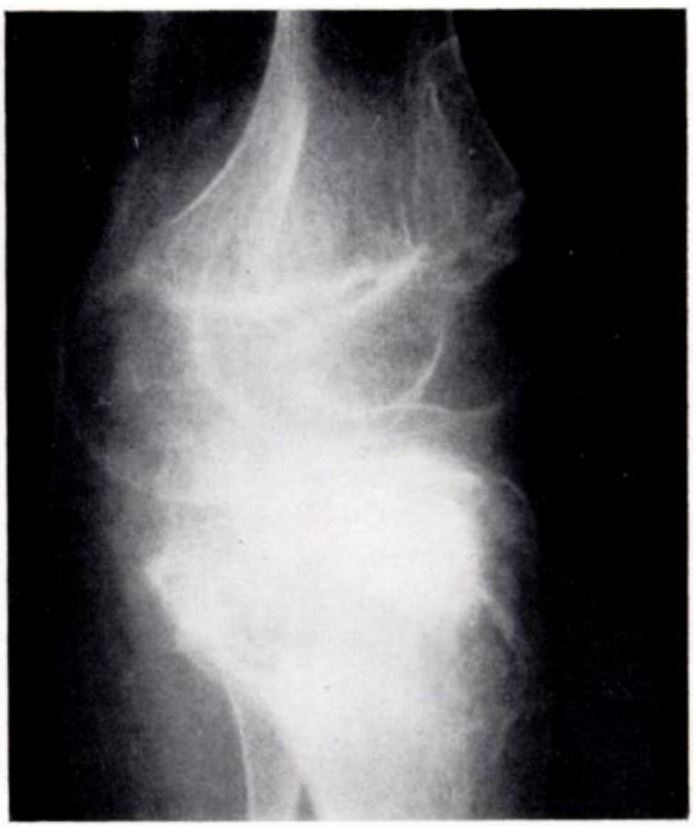

FIG. 9

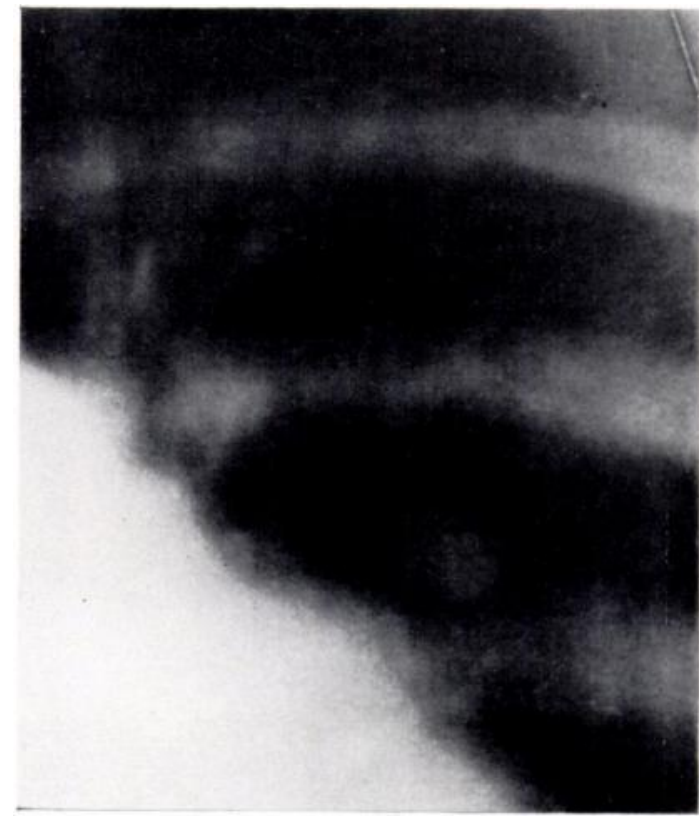

Fig. 11

Radiographs of the right knee in November 1969. Figure 8-The antero-posterior view shows a shell of new bone over the medial tibial condyle. Figure 9-The lateral view shows distortion and expansion of the cortex of the tibial epiphysis posteriorly. Figure 10-An angiogram of the right knee in November 1969 showing the vascularity of the tumour. Figure 11-A tomograph of the lesion in the left lung discovered two years after amputation showing the sharp outline of the radio-opaque area. 
appearance with cells in well-defined lacunae (Figs. 4 and 5). No histological evidence of malignancy was demonstrated.

Subsequent course-After amputation a prosthesis was fitted and the patient's general progress was satisfactory. The amputation stump healed well, she remained in good health and two years after amputation was accepted as a student nurse. A routine chest radiograph at that time showed a small, solitary, nodular opacity in the apical region of the lower lobe of the left lung (Fig. 11). It was thought that this lesion might be a solitary secondary metastasis from the primary bone tumour and she was observed for two months in case further secondary nodules developed. The lesion remained unchanged and, at thoracotomy, a small round nodule 1.5 centimetres in diameter was removed from the apical segment of the lower lobe of the left lung. Two small subpleural nodules were also seen in the basal part of the lobe and one further nodule was felt in the upper lobe. Examination of the excised nodule showed a well-defined margin with a pseudocapsule of compressed lung tissue. Microscopically, large areas of closely packed small polygonal cells with well-defined margins and little intercellular stroma were interspersed with other areas in which the tissue resembled hyaline cartilage with the tumour cells in lacunae (Figs. 6 and 7). Calcification of the stroma was present in many areas and showed a typical pericellular arrangement (Fig. 7). The histological characteristics were similar to those of the primary tumour and a diagnosis of metastatic chondroblastoma was made.

The patient has continued as a student nurse, and remains in good health five years after the onset. Serial radiographs of the chest show an unchanging small opacity in the mid-zone of the left lung.

\section{DISCUSSION}

Jaffe and Lichtenstein (1942) in describing chondroblastoma as an entity, considered that it was a benign neoplasm. Subsequent authors have supported this view (Valls, Ottolenghi and Schajowicz 1951; Kunkel, Dahlin and Young 1956; Coley 1960; Smith, Graham and Smith 1962; Wright and Sherman 1964; Welsh and Meyer 1964; Dahlin 1967; Schajowicz and Gallardo 1970; Spjut, Dorfman, Fechner and Ackerman 1971). All these workers emphasised the benign nature of chondroblastoma, which occurred typically as an expanding lesion in the epiphysis of a long bone.

In a series of twenty-four cases of chondroblastoma (Dahlin 1967) six occurred in the upper epiphysis of the humerus, the most frequent site. Schajowicz and Gallardo (1970) reported sixty-nine cases occurring over a period of twenty-eight years, which represented 1.8 per cent of 3,500 cases of tumour or tumour-like lesions of bone. In this series the two most frequent sites were the upper end of the femur (fifteen cases) and the upper end of the tibia (thirteen cases); there were forty-four males and twenty-five females, and fifty-two tumours occurred between five and twenty-five years of age with a peak incidence in the second decade. Typically, the tumours occurred in the epiphyses of long bones and were of moderate size varying from 1 to 7 centimetres in diameter. They were found to occur in a wide variety of bones including hands and feet. Pain and tenderness were the most constant presenting symptoms. Radiologically, there was a central area of destruction sharply delineated and located eccentrically in the epiphysis; usually a thin margin of increased bone density was present, cystic change occasionally occurred and the bone cortex was frequently bulged out and thin. The resected specimen showed no pathognomonic features and consisted of grey encephaloid tissue with a thin sclerotic bone margin. Involvement of the articular cartilage was unusual but occasionally an extraosseous mass followed destruction of the bone cortex. Minute foci of calcification and, less commonly, cystic change were recognised.

Histologically, the tumours were composed of small cells with clearly defined margins and round or oval nuclei. The cells were loosely arranged in sheets with little stroma other than in the zones of chondroid appearance. Mitotic figures were sparse and multinucleated 
giant cells with five to forty nuclei were present in variable numbers. The stroma was cartilaginous in places, with foci of calcification which showed a characteristic lace-like pattern around degenerated chondroblasts.

Although these authors emphasise the benign nature of the tumours, there have been recent isolated case reports of chondroblastoma recurring locally and even metastasising (Sweetnam and Ross 1967; Kahn, Wood and Ackerman 1969; Schajowicz and Gallardo 1970; Spjut et al. 1971). Although local recurrence did not indicate malignant transformation, malignant potential of some of the growths was revealed after careful follow-up when metastases appeared. Lack of overt features of malignancy is thus the major difficulty in assessing the potential natural history of these tumours. The present report, in which benign histological features were present in the original, the recurring and the metastasising nodules emphasises this difficulty.

\section{SUMMARY}

1. A case of chondroblastoma occurring in the upper tibial epiphysis of the right leg of a girl aged fourteen is reported.

2. Because the tumour recurred the leg was amputated.

3. Pulmonary metastases appeared two years after amputation.

Professor H. A. Sissons of the Institute of Orthopaedics, Royal National Orthopaedic Hospital, London, and Dr D. C. Dahlin of the Mayo Clinic, Rochester, Minnesota, United States of America, confirmed the histological diagnosis of "benign" chondroblastoma both in the original biopsy and in the amputation specimen. Our gratitude is expressed for the help given.

\section{REFERENCES}

Coley, B. L. (1960): Neoplasms of Bone and Related Conditions. Second edition. New York City: Paul B. Hoeber, Inc.

Dahlin, D. C. (1967): Bone Tumors. Second edition. Springfield, Illinois: Charles C. Thomas, Publishers.

JAffe, H. L., and Lichtenstein, L. (1942): Benign Chondroblastoma of Bone. American Journal of Pathology, $18,969$.

Kahn, L. B., Wood, F. M., and ACkerman, L. V. (1969): Malignant Chondroblastoma-Report of Two Cases and Review of the Literature. Archives of Pathology, 88, 371.

Kunkel, M. G., Dahlin, D. C., and Young, H. H. (1956): Benign Chondroblastoma. Journal of Bone and Joint Surgery, 38-A, 817.

Schajowicz, F., and Gallardo, H. (1970): Epiphysial Chondroblastoma of Bone. Journal of Bone and Joint Surgery, 52-B, 205.

Smith, D. A., Graham, W. C., and Smith, F. R. (1962): Benign Chondroblastoma of Bone. Journal of Bone and Joint Surgery, 44-A, 571.

Spjut, H. J., Dorfman, H. D., Fechner, R. E., and Ackerman, L. V. (1971): Tumors of Bone and Cartilage. Atlas of Tumor Pathology. Second series, fascicle five. Washington, D.C.: Armed Forces Institute of Pathology.

Sweetnam, R., and Ross, K. (1967): Surgical Treatment of Pulmonary Metastases from Primary Tumours of Bone. Journal of Bone and Joint Surgery, 49-B, 74.

Valls, J., Ottolenghi, C. E., and Schajowicz, F. (1951): Epiphyseal Chondroblastoma of Bone. Journal of Bone and Joint Surgery, 33-A, 997.

Welsh, R. A., and Meyer, A. T. (1964): A Histogenetic Study of Chondroblastoma. Cancer, 17, 578.

Wright, J. L., and Sherman, M. S. (1964): An Unusual Chondroblastoma. Journal of Bone and Joint Surgery, 46-A, 597. 